\title{
Extinction risk modeling predicts range-wide differences of climate change impact on Karner blue butterfly
}

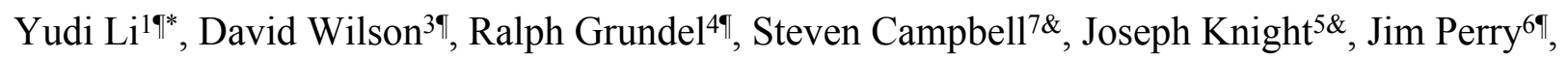
7 Jessica J. Hellmann ${ }^{29}$

${ }^{1}$ Energy Graduate Group, University of California Davis, Davis, CA, 95616

${ }^{2}$ Conservation Sciences Graduate Program, University of Minnesota, St. Paul, MN, 55108

${ }^{3}$ Minnesota Department of Natural Resources, Grand Rapids, MN, 55744

${ }^{4}$ Lake Michigan Ecological Research Station, US Geological Survey, Chesterton, IN, 46304

${ }^{5}$ Department of Forest Resources, University of Minnesota, St. Paul, MN, 55108

${ }^{6}$ Department of Fisheries, Wildlife and Conservation Biology University of Minnesota, St. Paul, MN, 55108

${ }^{7}$ Albany Pine Bush Preserve Commission, Albany Pine Bush, NY, 12205

8

11 qThese authors contributed equally to this work.

12 \&These authors also contributed equally to this work.

13

$14 *$ Corresponding author

15 E-mail: evoli@ucdavis.edu 


\section{Abstract}

The Karner blue butterfly (Lycaeides melissa samuelis), an endangered species in decline due to multiple factors, including habitat loss, can be further threatened by climate change. Evaluating how climate shapes the population dynamics and distribution of the Karner blue (Kbb) is necessary for developing adaptive. Demographic models generally used for insect populations are often either density-dependent or applied to population presence-absence data in a densityindependent manner. In contrast, we used scale-based, mixed density-dependent and densityindependent (hereafter "endo-exogenous") models for the $\mathrm{Kbb}$, based on long-term count data of abundance during flight periods, to understand how different environmental variables, including climate, affected $\mathrm{Kbb}$ extinction risk through the middle of the 21 st century. Our endoexogenous models showed that density-dependent and environmental variables, including climate, topography, and tree canopy coverage, were essential drivers of Kbb population dynamics. We also found that Kbb's response to climate differed between the species' two annual generations and across its range: higher temperature and precipitation in summer generally benefited the second-generation populations, whereas there were uncertainties of the effects on the populations in different ecoregions during the first generation. These results imply that population-specific biotic/abiotic factors need to be incorporated into plans to manage the recovery of $\mathrm{Kbb}$ under climate change.

\section{Introduction}

Effects of climate change on biodiversity and ecosystems are well-documented [1-4], including changes in morphology, phenology, and species distributions [5-8]. Insects can be valuable indicators of how species respond to climate change [7-12] because they are ectotherms and are widespread across heterogeneous landscapes [13-14]. They also have complex life cycles with varying vulnerability throughout their life spans, challenging us to understand multiple ways in which climate change can affect a single species [15-16].

Widespread, increasing extinction risk has been documented across insect orders [60]. Therefore, improving the ability to predict extinction risk and relating that to drivers affecting that extinction risk is an important tool for conservation planning for at-risk species [61-63]. Elsewhere, we modeled extinction risk for an endangered butterfly, the Karner blue butterfly (Kbb, Lycaeides melissa samuelis), using an approach that incorporates both density-dependent and density-independent effects. We evaluated how density-dependent and density-independent factors might affect Kbb population size across generations.

The thermal regime controls the survival of many ectothermic organisms [17-19]. Climate change projections for the Midwest and the Northeastern United States (U.S.) predict higher temperatures, especially during the winter [20-21]. This could undermine the fitness of insect species [22] if it causes earlier maturation and smaller body sizes [23-24]. However, under warmer conditions and faster development, extra generations may appear, as has been reported for some species [25-27]. 
Precipitation patterns are varied due to climate change, and rainfall can be as significant as the temperature in affecting demography [28-29]. For insects, in particular, the effects of rain on demography can be complex and vary with temporal and spatial scales. For example, rainfall can interfere with pollen transport and dilute nectar, leading to lower pollinator visitation rates and poorer host plant reproduction [30-31]. In fact, for some butterfly species, total monthly precipitation is a better predictor of abundance than temperature and relative humidity [32-33].

Microclimates are mainly determined by terrain and canopy coverage [34]. Topographic conditions (i.e., slope, aspect, elevation) usually are decoupled from broad climatic gradients [35-37]. Wind speed/direction and solar radiation are affected by landscape texture [38] and, in turn, influence local thermal and rainfall patterns [39]. For instance, south-facing slopes are generally warmer than north-facing slopes in the northern hemisphere (Geiger et al., 2009). Higher elevations are colder and drier than lower altitudes [38]. This suggests that population survival models should incorporate fine-scaled, topo-climatic variables [41-43].

Multiple species in the butterfly family Lycaenidae share traits that make them prone to endangerment [44], including limited dispersal ability, monophagy or limited hostplant species, and specific habitat configuration requirements. The Kbb was listed as federally endangered in 1992 [48-49]. Today, native populations exist in isolated locations in New York, Michigan, and Wisconsin, U.S.; some have been reintroduced in Ohio, New Hampshire, Minnesota, U.S. [4547]. The Kbb has an inherently limited dispersal range (less than $1 \mathrm{~km}$ ), and habitat fragmentation further restricts their range expansion [49-50]. It resides in high-quality oak savanna and pine barren habitats, the landscape that supports its sole host plant, wild blue lupine (Lupinus perennis).

These landscapes have declined for decades due to fire suppression, agricultural expansion, and urbanization [54-56]. In recent years, oak savanna - pine barren areas have experienced new climate patterns, including prolonged summer drought and milder springs and winters. Specialist butterflies like the Kbb may be particularly susceptible to temperature changes if their hostplants are negatively affected by drought and other conditions, for example, host plant availability throughout the growing season [57-59]. Such influences may directly cause declines in Kbb survivorship and reproduction [60].

As a bivoltine species, first-generation Kbbs overwinter as an egg until mid-April, mature from larva to pupa through late May, and experience peak flight of emerging first-generation adults in June. In July, a second generation begins with peak flight and egg-laying in August [65]. The second generation is typically three to four times more abundant than the first generation [51, 66-67]. Thermal and drought tolerances are usually specific to each life stage [67-70], and climatic stress experienced by one stage can influence the next through 'carry-over effects' [71]. Conditions experienced by one generation also affect subsequent generations through 'transgenerational effects' [72-74]. Both carry-over and transgenerational effects are important considerations when modeling Kbb responses to temperature [75-76] to ensure that impacts throughout the life stages are modeled [77-79]. 
In a population viability analysis of the Kbb, [80] ranked the loss of habitat, fragmentation, and weather-related loss of eggs/larvae as critical bottlenecks for Kbb population viability. Several of these effects exhibited density dependency. Loss of overwintering eggs, effects of variable spring temperature and precipitation on larval survival, and effects of stress (often drought-induced) on hostplants affecting larval survival later in the year were climate change sensitive aspects of the Kbb life history that were most critical in determining population viability.

Here we modeled the effects of climate trends on both generations of the Kbb to identify

\section{Materials and Methods}

\section{Density-Dependent Data}

We used time-series count data of adult Kbb from five populations across the species' range as the source of information on past population trends in Kbb abundance (S1 Table 1). Four populations were located on oak savannas in the Midwest U.S., and the fifth was found in eastern U.S. pine barrens habitats (Fig 1). Researchers sampled existing populations annually over time frames of $8-27$ years at 48 sites in three states (Indiana, New York, Wisconsin), counting adult $\mathrm{Kbb}$ present along linear transects during the flight period - from late May to late June for the first generation, and from mid-July to mid-August for the second generation (S1 Table 2). Each of the five population groups was in a distinct ecoregion (S1 Fig 1) [84]. All populations within a given ecoregion were surveyed with consistent sampling strategies through time, usually by the same research teams at each location, allowing us to model across sites within the same ecoregions.

Fig 1. Locations of Karner blue butterfly's habitats in Central Wisconsin, Northwest Wisconsin, Fort McCoy (Wisconsin), Indiana Dunes National Park, and Albany Pine Bush (New York). White filled circles represent extant Karner populations, open circles represent historical Karner populations that are now extinct, and yellow filled circles represent sites with Karner reintroduction management ongoing.

Transect widths were not consistent among regions, so we calculated a population density index across all the surveys during each generation per site expressed as the number of individuals per kilometer of the transect. Although periodic habitat management at the sites, such 
as mowing and burning, resulted in changes in vegetation conditions, variance caused by different management practices was not explicitly considered but may have affected our results. We assessed density-dependent effects for each generation by including flight-period population densities of the previous two generations. Including generations from more than the last year was unlikely to increase explanatory power [85].

\section{Density-Independent Data}

We downloaded monthly climatic data (S1 Table 3) from the Parameter-elevation Relationships on Independent Slopes Model (PRISM Climate Group) as raster maps at a resolution of 30 arc-seconds (1/40th of a decimal degree). Each pixel was $800 \mathrm{~m}$ x $800 \mathrm{~m}$ [86]. PRISM's temperature and precipitation are gridded interpolations of climate data and digital elevation models (DEM) [87-88]. As environmental factors vary throughout the growing season, it was necessary to examine the two generations separately to understand their interactions with Kbb life cycles [89-90].

For each Kbb population, we used monthly climatic data corresponding to the location and time over which surveys were conducted. We examined four climate variables - monthly minimum, maximum, and mean temperature, and total precipitation - over periods approximating three life stages: egg (Dec-Mar as overwintering), larvae and pupae (Apr-May as spring), and peak adulthood (Jun) for the first generation; egg (Jun), larvae and pupae (Jul), and peak adulthood (Aug) for the second generation.

We included two additional topographic variables: slope and aspect. They were derived from 30 m DEMs obtained from USGS (U.S. Geological Survey) in ArcGIS [91]. The circular aspect layer was converted to a topographic solar radiation index (i.e., trasp), using the following linear transformation:

The transformation output was a continuous variable between 0 and 1 where north-oriented slopes were assigned 0 , and south-oriented slopes were given 1 [92].

We also extracted canopy coverage from the 2011 National Land Cover Database (NLCD) and USFS Tree Canopy Cover for CONUS from the Multi-Resolution Land Characteristics (MRLC) Consortium at $30 \mathrm{~m}$ resolution [93]. We assumed that both topography and tree canopy cover had been constant over the past two decades at the level of individual sites [51].

\section{Modeling Process}

We combined our density data with environmental explanatory variables to create endoexogenous models using 18 predictor variables per generation. Our statistical models were built at two spatial scales: i) population grouped by each ecoregion, and ii) all populations combined across ecoregions. We modeled population group as the unit rather than specific populations for 
three reasons: first, density estimates for each population were too small to create robust models; second, variation among transect measurements at an individual site could be very high, particularly when local population density was low; third, there was no variance of topography or canopy cover within individual sites. Sample sizes and the number of years surveyed in our data set varied among regions (S1 Table 1). Therefore, when integrating all populations, we reduced estimation bias using bootstrapping to balance oversampled and underrepresented population groups, following [94-95].

We applied six modeling algorithms of R package "caret" [96] to check model performance with mean absolute error, root-mean-square error, and adjusted R-squared: two were regressionbased (i.e., generalized linear model and multivariate additive regression spline, and four were machine-learning (i.e., random forest, gradient boost machines, support vector machines, neural network analysis). We preprocessed low-variance and colinear predictors to reduce the highdimensionality of data space and standardized variables in regression-based algorithms with centering and scaling. After reviewing initial models (S1 Table 4), we limited further modeling efforts to the use of random forests, a non-parametric approach that did exceptionally well for multivoltine species, guaranteeing robust model outputs in other studies [97-98].

We then used the genetic algorithm (GA) for selection among random forest models [99]. Genetic algorithm, as a computationally efficient approach, generated an entire population of feasible solutions that were repeatedly subjected to "cross-over" and "random mutation" until the combinatorial optimum with the lowest Akaike Information Criterion (AIC) was identified [100]. A concern with GA applications is the potential to overfit the models. Therefore, we also applied jack-knife partial least squares (PLS) using the R package "mdatools" [101]. This linear latent approach is suitable when the matrix of predictors has more variables than observations [102], identifying the estimated coefficient, standard error, and $\mathrm{p}$-value of each predictor. The sample $\mathrm{R}$ codes were included in S2 Appendix.

\section{Ethics Statement}

The study did not involve human subjects, vertebrates, or cephalopods, nor any kind of animal sacrifice. It did involve observational and field studies of a federally listed endangered species - Karner blue butterfly. Approval from the U.S. Fish and Wildlife Service and relevant state agencies to conduct $\mathrm{Kbb}$ counts were obtained when required by those agencies. Data were collected on federal, state, and non-governmental organization lands managed by the U.S. National Park Service (Indiana Dunes National Park populations), U.S. Department of Defense (Fort McCoy populations), and the Albany Pine Bush Commission (Albany Pine Bush populations), with the permission of those entities. For the Central and Northwest Wisconsin populations, all the surveys were legally carried out on public-access land (state- and county-owned, or public access rights-of-way immediately along public roads) without intentionally handling, harassing, or taking specimens. 


\section{Results}

For the first generation, the population density of both first and second generations in the previous year were positively related to current-generation density, except the populations of Northwest Wisconsin (Table 1). Among 12 climate variables, population density increased with warmer overwintering minimum temperature at the whole-species scale in Central Wisconsin and decreased in Fort McCoy and Albany Pine Bush; it also reduced with higher overwinter and spring total precipitation except in Northwest Wisconsin. In contrast, none of the June predictors and spring minimum temperature were significant in any ecoregion. Specifically, in populations of Northwest Wisconsin and Indiana Dunes National Park, canopy cover, elevation, slope, and trasp were negatively associated with current-generation density.

Table 1. Best-fit endo-exogenous partial least squares regression model regression coefficients at whole-species scale and (five) ecoregion for the first-generation Kbb populations, separately. The adjusted- $\mathrm{R}^{2}$ values were attached to the last row of the table.

\begin{tabular}{|c|c|c|c|c|c|c|c|c|c|c|c|c|c|c|c|c|c|c|}
\hline & \multicolumn{3}{|c|}{$\begin{array}{l}\text { Whole } \\
\text { Species }\end{array}$} & \multicolumn{3}{|c|}{$\begin{array}{c}\text { Central } \\
\text { Wisconsin }\end{array}$} & \multicolumn{3}{|c|}{$\begin{array}{l}\text { Northwest } \\
\text { Wisconsin }\end{array}$} & \multicolumn{3}{|c|}{$\begin{array}{c}\text { Fort } \\
\text { McCoy }\end{array}$} & \multicolumn{3}{|c|}{$\begin{array}{l}\text { Indiana Dunes } \\
\text { National Park }\end{array}$} & \multicolumn{3}{|c|}{$\begin{array}{c}\text { Albany } \\
\text { Pine Bush }\end{array}$} \\
\hline & $\mathrm{EC}$ & $\mathrm{SE}$ & $\mathrm{p}$ & EC & $\mathrm{SE}$ & $\mathrm{p}$ & EC & $\mathrm{SE}$ & $\mathrm{p}$ & $\mathrm{EC}$ & $\mathrm{SE}$ & $\mathrm{p}$ & $\mathrm{EC}$ & $\mathrm{SE}$ & $\mathrm{p}$ & $\mathrm{EC}$ & $\mathrm{SE}$ & $\mathrm{p}$ \\
\hline PS & 0.38 & 0.08 & 0.007 & 0.25 & 0.10 & 0.050 & 0.08 & 0.06 & 0.230 & 0.77 & 0.10 & 0.001 & 0.58 & 0.08 & 0.002 & 0.48 & 0.10 & 0.007 \\
\hline $\mathrm{PF}$ & 0.23 & 0.06 & 0.014 & 0.17 & 0.05 & 0.029 & & & & & & & 0.32 & 0.04 & 0.001 & & & \\
\hline MT_OW & & & & & & & & & & & & & & & & -0.10 & 0.03 & 0.036 \\
\hline MT_SP & 0.05 & 0.02 & 0.040 & & & & & & & 0.04 & 0.05 & 0.125 & & & & & & \\
\hline \multicolumn{19}{|l|}{ MT_JN } \\
\hline AT_OW & & & & & & & & & & & & & & & & -0.02 & 0.03 & 0.026 \\
\hline AT_SP & 0.05 & 0.01 & 0.010 & 0.09 & 0.03 & 0.056 & & & & & & & & & & & & \\
\hline \multicolumn{19}{|l|}{ AT_JN } \\
\hline IT_OW & 0.03 & 0.01 & 0.072 & 0.14 & 0.03 & 0.024 & & & & -0.11 & 0.06 & 0.022 & & & & -0.14 & 0.01 & 0.001 \\
\hline \multicolumn{19}{|l|}{ IT_SP } \\
\hline \multicolumn{19}{|l|}{ IT_JN } \\
\hline PT_OW & & & & & & & & & & -0.22 & 0.04 & 0.004 & -0.14 & 0.06 & 0.088 & -0.19 & 0.04 & 0.008 \\
\hline PT_SP & -0.21 & 0.03 & 0.003 & -0.35 & 0.03 & 0.000 & & & & -0.18 & 0.08 & 0.085 & & & & & & \\
\hline \multicolumn{19}{|l|}{ PT_JN } \\
\hline Canopy & & & & & & & -0.03 & 0.01 & 0.060 & & & & -0.02 & 0.01 & 0.074 & & & \\
\hline Elevation & & & & & & & -0.08 & 0.02 & 0.014 & & & & -0.04 & 0.06 & 0.380 & & & \\
\hline Slope & & & & & & & -0.04 & 0.01 & 0.011 & & & & -0.03 & 0.03 & 0.254 & & & \\
\hline Trasp & & & & & & & -0.04 & 0.01 & 0.018 & & & & -0.01 & 0.07 & 0.263 & & & \\
\hline $\operatorname{adj}-R^{2}$ & & 0.409 & & & 0.418 & & & 0.606 & & & 0.42 & & & 0.75 & & & 0.61 & \\
\hline
\end{tabular}


For the second generation, four variables were significant across spatial scales and among ecoregions: population density of previous-year second-generation (positive), current-year first generation (positive), August maximum temperature (positive in Northwest Wisconsin and Fort McCoy, and negative in Central WI and at whole-species scale), and July total precipitation (positive, except in Fort McCoy and Albany Pine Bush) (Table 2). Total precipitation for June and August were the only variables not significant in any ecoregion. Canopy cover was positively associated with current-generation density in Northwest Wisconsin but negative in Indiana Dunes National Park. The three topographic predictors were consistently negative in Indiana Dunes National Park but insignificant.

Table 2. Best-fit endo-exogenous partial least squares regression model regression coefficients at whole-species scale and (five) ecoregion for the second-generation Kbb populations, separately. The adjusted- $\mathrm{R}^{2}$ values were attached to the last row of the table.

\begin{tabular}{|c|c|c|c|c|c|c|c|c|c|c|c|c|c|c|c|c|c|c|}
\hline & \multicolumn{3}{|c|}{$\begin{array}{l}\text { Whole } \\
\text { Species }\end{array}$} & \multicolumn{3}{|c|}{$\begin{array}{c}\text { Central } \\
\text { Wisconsin }\end{array}$} & \multicolumn{3}{|c|}{$\begin{array}{l}\text { Northwest } \\
\text { Wisconsin }\end{array}$} & \multicolumn{3}{|c|}{$\begin{array}{l}\text { Fort } \\
\text { McCoy }\end{array}$} & \multicolumn{3}{|c|}{$\begin{array}{l}\text { Indiana Dunes } \\
\text { National Park }\end{array}$} & \multicolumn{3}{|c|}{$\begin{array}{c}\text { Albany } \\
\text { Pine Bush }\end{array}$} \\
\hline & $\mathrm{EC}$ & $\mathrm{SE}$ & $\mathrm{p}$ & EC & $\mathrm{SE}$ & $\mathrm{p}$ & EC & SE & $\mathrm{p}$ & EC & SE & $\mathrm{p}$ & $\mathrm{EC}$ & SE & $\mathrm{p}$ & $\mathrm{EC}$ & SE & $\mathrm{p}$ \\
\hline CF & 0.36 & 0.08 & 0.013 & 0.38 & 0.10 & 0.052 & & & & 0.16 & 0.04 & 0.010 & 0.48 & 0.11 & 0.012 & 0.68 & 0.15 & 0.011 \\
\hline PS & 0.24 & 0.08 & 0.045 & 0.18 & 0.07 & 0.062 & 0.06 & 0.02 & 0.019 & 0.18 & 0.05 & 0.016 & 0.35 & 0.07 & 0.009 & 0.17 & 0.10 & 0.039 \\
\hline MT_JN & & & & & & & & & & & & & & & & 0.07 & 0.04 & 0.198 \\
\hline MT_JL & & & & & & & & & & 0.08 & 0.01 & 0.003 & & & & & & \\
\hline MT_AG & & & & 0.03 & 0.01 & 0.053 & 0.03 & 0.02 & 0.074 & & & & & & & 0.05 & 0.02 & 0.035 \\
\hline AT_JN & & & & & & & & & & & & & 0.05 & 0.03 & 0.089 & & & \\
\hline $\mathrm{AT}_{-} \mathrm{JL}$ & -0.04 & 0.02 & 0.063 & & & & & & & 0.07 & 0.02 & 0.037 & & & & & & \\
\hline AT_AG & -0.06 & 0.03 & 0.098 & -0.06 & 0.02 & 0.032 & 0.03 & 0.01 & 0.025 & 0.10 & 0.02 & 0.007 & & & & & & \\
\hline IT_JN & 0.06 & 0.02 & 0.019 & 0.03 & 0.02 & 0.249 & 0.02 & 0.01 & 0.016 & & & & & & & & & \\
\hline IT_JL & & & & & & & 0.05 & 0.02 & 0.094 & 0.09 & 0.01 & 0.001 & & & & & & \\
\hline IT_AG & & & & & & & & & & & & & & & & 0.06 & 0.03 & 0.068 \\
\hline \multicolumn{19}{|l|}{ PT_JN } \\
\hline PT_JL & 0.06 & 0.02 & 0.019 & 0.08 & 0.06 & 0.025 & 0.04 & 0.03 & 0.024 & & & & 0.08 & 0.05 & 0.062 & & & \\
\hline \multicolumn{19}{|l|}{ PT_AG } \\
\hline Canopy & & & & & & & 0.06 & 0.02 & 0.049 & & & & 0.02 & 0.03 & 0.304 & & & \\
\hline Elevation & & & & & & & & & & & & & -0.02 & 0.05 & 0.306 & & & \\
\hline Slope & -0.07 & 0.02 & 0.011 & & & & & & & & & & -0.07 & 0.06 & 0.293 & & & \\
\hline Trasp & & & & & & & & & & & & & -0.06 & 0.03 & 0.154 & & & \\
\hline $\operatorname{adj}-R^{2}$ & & 0.468 & & & 0.447 & & & 0.523 & & & 0.478 & & & 0.785 & & & 0.733 & \\
\hline
\end{tabular}

EC, Estimated Coefficient; SE, Standard Error; p, p-value; PS, Previous-Year Second-Generation Density; PF, 
Adjusted $\mathrm{R}^{2}$ of model equations ranged from 0.22 to 0.85 , with values smaller at wholespecies than ecoregion scale, and more significant in Northwest Wisconsin, Indiana Dunes National Park, and Albany Pine Bush (Tables 1 and 2). Not all variables kept in the equations were statistically significant, especially for the populations of Indiana Dunes National Park, because GA provided combinatorial optimization. Estimated coefficients of density-dependent variables $(0.06-0.68)$ were almost twice as large as those of density-independent variables $(0.01-0.22)$. In addition, the standard errors of climatic variables were generally small $(0.01-3.00)$. They were much smaller than their estimated coefficients, indicating relatively high certainty about our understanding of $\mathrm{Kbb}$ responses to climate change.

\section{Discussion}

Best-fit PLS models differed among generations and ecoregions. Still, at least one densitydependent variable, previous-year second-generation population density, and several densityindependent variables were retained in each model equation, suggesting that both influence population dynamics of the Kbb across its range [103]. However, consistent with [104-105], we found density-dependence is always more influential than any density-independent environmental factors, implicating that climatic effects could be overshadowed by density-dependent effects in the absence of persistent ecological changes and extreme climate events [106-107] and that the positive density dependence in the models, in the form of steadily decreasing population trends, might have been related to population bottlenecks and Allee effects [108-109].

We also found that the population size of the first generation was consistently smaller than the second generation in the same year, and that might have been influenced by the timing of wild lupine growth: first-generation larvae survive several months overwinter and feed on smaller, newly sprouted wild lupine leaves as the insects emerge from dormancy; second-generation larvae hatch a week after eggs are laid on mature lupine leaves which can have better nutrient quality [109-110]. However, [111] found that leaf nutrients were even poorer in the second generation, because of worsening climate conditions, such as drought, in the summer. Thus, an alternative explanation could be that high overwinter mortality of eggs drove down overall population abundance.

The detrimental effects of higher overwinter temperatures and total precipitation on the first-generation flight-period density in most ecoregions and the whole-species model were consistent with previous research on the butterflies in the UK [112-115]. [108] showed three major mechanisms to be essential to overwinter survival of Kbb. First, higher temperature causes snow cover to thaw more quickly, increasing the chance of overwintering stage exposure due to loss of insulation [116]. Second, warm, moist conditions might cue earlier hatching during late winter, resulting in mortality of hatched individuals because of limited food sources [117-119]. Third, overwintering diseases, such as fungal infections, increase with elevated temperature and precipitation [120]. 
Elevated spring temperatures were positively associated with first-generation flight-period density, suggesting that spring temperature might be critical to the final larval instar stage, accelerating metamorphosis [121]. In addition, higher temperatures during the pupal stage have been demonstrated to cause earlier maturation in other butterfly species, including the Eastern monarch butterfly [122-125]. However, for the Kbb, like other multivoltine species, earlier maturation often results in smaller adult sizes and reduced fitness [126-127]. The solid adverse effects of higher spring total precipitation on some populations were indicative that rainfall shortage might not necessarily hamper larval and pupal developments, and wild lupine was relatively drought-tolerant, supporting the negative association between seasonal butterfly abundance and spring monthly precipitation observed in previous research on butterflies in neotropics [128].

There was a strong, positive association between flight-period density and temperature for the second generation. [129] reported that warm summers were generally beneficial to multivoltine species for several reasons. First, higher June mean and minimum temperature might promote better host plant quality (i.e., wild lupine), thus enhancing larval feeding and providing a longer growing season with increased sunny days. Second, higher July temperatures could lead to earlier adult emergence, with a higher probability that a third generation would be produced [123]. Third, lower August temperatures (maximum temperature, in particular) may result in localized extinction [130-131]. In contrast, a warmer August may facilitate the growth of plants as food sources for the Kbb during extended flight periods [132]. There is also evidence that higher August temperature correlates with enhanced egg-laying rate, so the benefit of warming could be passed to the next overwinter generation [133].

The uniformly positive influence of increased total summer precipitation, especially in July, suggests that rainfall may partially alleviate water stress [134-135]. In recent decades, the extinction of populations at Indiana Dunes National Park has been attributed to summer drought [119]. Such drought led to the desiccation of host and nectar plants, impairing Kbb reproduction [33]. Therefore, according to our model outputs, a combination of temperature, precipitation, and density dependence best predicted Kbb population dynamics. Consistent with the finding of [136139], monthly climate predictors, like mean temperature and total precipitation, had twice the explanatory power for $\mathrm{Kbb}$ abundance as did extreme climate predictors, perhaps because the monthly climate had more direct and proximal influences on their physiological responses. Temperature can positively affect cold-adapted insect species except during winter [140]. It's possible that elevated temperature enabled individuals to reach their physiological optimum [141], overriding the harmful effects of a warmer winter [142]. The mean temperature was often considered the primary climatic driver for some pollinator species [143-145]. However, our study showed that minimum and maximum temperatures, and total precipitation (especially in spring and July), appeared to be as crucial as mean temperature.

Effects of tree canopy on Kbb population density were mixed between the two generations since we found that more extensive canopy cover led to the decline of the first-generation 
population and the reverse for the second generation. In early spring, canopy gaps could promote lupine photosynthetic activity [146], compensating for relatively low atmospheric and soil temperatures [147]. In summer, extensive canopy shading might not only offer thermal refugia for the $\mathrm{Kbb}[111,149]$, but suitable moisture conditions for lupine and other nectar species, preventing them from senescing too early [149-151]. However, canopy shading caused a tradeoff limiting host and nectar plant growth due to insufficient solar radiation [152]. Thus, an intermediate canopy cover with moderate shading might best be able to support a high abundance of Kbb [111, 153156]. In addition, adverse effects of both slope and trasp were consistent with the findings of [157158]: north- and east-facing gentle slopes were much cooler than south- and west-facing steep slopes in the northern hemisphere, leading to higher survivorship of wild lupine and reproductive success of the butterflies.

Microclimate variables were not as instructive as coarse-scale climatic factors except in Indiana Dunes National Park and Northwest Wisconsin. Habitat specialist species, like the Kbb, can have a more significant margin of thermal tolerance at the northern edge than at the southern edge of their range in the northern hemisphere [9, 18, 81, 159]. This asymmetrical response to thermal gradients [19] could explain why we found that none of the climatic variables were significant for Northwest Wisconsin populations during the first generation. Northwest Wisconsin is located at the northern edge of the current $\mathrm{Kbb}$ range, where annual temperatures were lowest and growing seasons were shortest among the five ecoregions. Under these conditions, lupine quality and phenology could be a more substantial limiting factor than climate [160-161]. In contrast, Indiana Dunes National Park is located close to the southern edge of the range and often experiences mild winters, cool summers, and high humidity because it is adjacent to Lake Michigan [162]. These ideal climate conditions may have buffered Kbb populations against the geographical gradient effects until the long-lasting drought of 2012.

\section{Conclusions}

Examining both generations separately helped identify the timing of long-term effects of temperature and precipitation on lifecycles: the first-generation adult stage typically showed lower sensitivity to climate variables compared to the second generation. As did [129], we found that unusually low temperatures under climate change might be tolerated by overwintering eggs, and high temperatures were beneficial to all the other life stages of the $\mathrm{Kbb}$, while water stress is a significantly limiting factor during the summer. The effects of weather conditions on earlier life stages or the previous generation could be carried over to later life stages or the subsequent generation, altering survivorship and population abundance. In addition, population-specific differences of significant variables may suggest local adaptation because each ecoregion had a unique combination of climate, topography, soil, hydrology, and plant communities. Conversely, the integration of all populations across regions obscured the patterns of local spatial heterogeneity. Therefore, confirming the finding of [163], models at ecoregion or finer scales appear to be 
preferable to whole-species levels for conservation purposes and for directing management plans. Because most previous studies either used density-dependent models or were based on presenceabsence data rather than population count data, our study adds new insight into how the Kbb might respond to various climate change effects.

\section{Acknowledgments}

This study was conducted at the University of Minnesota in collaboration with the Institute on the Environment. We thank members of the Karner blue butterfly Recovery Team. We especially acknowledge the contributors of Karner blue population count data: Randy Knutson (US National Park Service), Ann Swengel and Scott Swengel (independent researchers), Chelsea Gunther (Wisconsin DNR) and Tim Wilder (Department of Defense, Fort McCoy), Steven Campbell and Neil Gifford (Albany Pine Bush Preserve), and Christopher Hoving (Michigan DNR). Their data are the foundation of the thesis on which this paper was based.

\section{References}

1. Sparks TH, Carey PD. The responses of species to climate over two centuries: an analysis of the Marsham phenological record, 1736-1947. Journal of Ecology. 1995 Apr 1:321-9.

2. Walther GR, Post E, Convey P, Menzel A, Parmesan C, Beebee TJ, et al. Ecological responses to recent climate change. Nature. 2002 Mar;416(6879):389-95.

3. Pearson RG. Climate change and the migration capacity of species. Trends in ecology \& evolution. 2006 Mar 1;21(3):111-3.

4. Cramer W, Yohe G, Field CB. Detection and attribution of observed impacts. Cambridge University Press; 2014.

5. Parmesan C, Ryrholm N, Stefanescu C, Hill JK, Thomas CD, Descimon H, et al. Poleward shifts in geographical ranges of butterfly species associated with regional warming. Nature. 1999 Jun;399(6736):579-83.

6. Parmesan C, Yohe G. A globally coherent fingerprint of climate change impacts across natural systems. nature. 2003 Jan;421(6918):37-42.

7. Root TL, Price JT, Hall KR, Schneider SH, Rosenzweig C, Pounds JA. Fingerprints of global warming on wild animals and plants. Nature. 2003 Jan;421(6918):57-60.

8. Møller AP, Rubolini D, Lehikoinen E. Populations of migratory bird species that did not show a phenological response to climate change are declining. Proceedings of the National Academy of Sciences. 2008 Oct 21;105(42):16195-200.

9. Warren MS, Hill JK, Thomas JA, Asher J, Fox R, Huntley B, et al. Rapid responses of British butterflies to opposing forces of climate and habitat change. Nature. 2001 Nov;414(6859):65-9. 
10. Wilson RJ, Gutiérrez D, Gutiérrez J, Martínez D, Agudo R, Monserrat VJ. Changes to the elevational limits and extent of species ranges associated with climate change. Ecology letters. 2005 Nov;8(11):1138-46.

11. Pöyry J, Luoto M, Heikkinen RK, Kuussaari M, Saarinen K. Species traits explain recent range shifts of Finnish butterflies. Global Change Biology. 2009 Mar;15(3):732-43.

12. Diamond SE, Frame AM, Martin RA, Buckley LB. Species' traits predict phenological responses to climate change in butterflies. Ecology. 2011 May;92(5):1005-12.

13. Bickford DP, Sheridan JA, Howard SD. Climate change responses: forgetting frogs, ferns and flies?. Trends in ecology \& evolution. 2011;11(26):553-4.

14. Ohlberger J. Climate warming and ectotherm body size-from individual physiology to community ecology. Functional Ecology. 2013 Aug;27(4):991-1001.

15. Radchuk V, Turlure C, Schtickzelle N. Each life stage matters: the importance of assessing the response to climate change over the complete life cycle in butterflies. Journal of Animal Ecology. 2013 Jan;82(1):275-85.

16. Buckley LB, Nufio CR, Kirk EM, Kingsolver JG. Elevational differences in developmental plasticity determine phenological responses of grasshoppers to recent climate warming. Proceedings of the Royal Society B: Biological Sciences. 2015 Jun 22;282(1809):20150441.

17. Overgaard J, Sørensen JG. Rapid thermal adaptation during field temperature variations in Drosophila melanogaster. Cryobiology. 2008 Apr 1;56(2):159-62.

18. Sunday JM, Bates AE, Kearney MR, Colwell RK, Dulvy NK, Longino JT, et al. Thermal-safety margins and the necessity of thermoregulatory behavior across latitude and elevation. Proceedings of the National Academy of Sciences. 2014 Apr 15;111(15):5610-5.

19. Araújo MB, Ferri-Yáñez F, Bozinovic F, Marquet PA, Valladares F, Chown SL. Heat freezes niche evolution. Ecology letters. 2013 Sep;16(9):1206-19.

20. Clusella-Trullas S, Blackburn TM, Chown SL. Climatic predictors of temperature performance curve parameters in ectotherms imply complex responses to climate change. The American Naturalist. 2011 Jun 1;177(6):738-51.

21. Hoffmann AA, Chown SL, Clusella-Trullas S. Upper thermal limits in terrestrial ectotherms: how constrained are they?. Functional Ecology. 2013 Aug;27(4):934-49.

22. Le Moullac G, Haffner P. Environmental factors affecting immune responses in Crustacea. Aquaculture. 2000 Nov 20;191(1-3):121-31.

23. Terblanche JS, Hoffmann AA, Mitchell KA, Rako L, le Roux PC, Chown SL. Ecologically relevant measures of tolerance to potentially lethal temperatures. Journal of Experimental biology. 2011 Nov 15;214(22):3713-25.

24. Horne CR, Hirst AG, Atkinson D. Temperature-size responses match latitudinal-size clines in arthropods, revealing critical differences between aquatic and terrestrial species. Ecology letters. 2015 Apr;18(4):327-35.

25. Fischer J, Phillips NE. Carry-over effects of multiple stressors on benthic embryos are mediated by larval exposure to elevated UVB and temperature. Global Change Biology. 2014 Jul;20(7):2108-16. 
26. Hopwood PE, Moore AJ, Tregenza T, Royle NJ. Niche variation and the maintenance of variation in body size in a burying beetle. Ecological Entomology. 2016 Feb;41(1):96104.

27. English S, Cowen H, Garnett E, Hargrove JW. Maternal effects on offspring size in a natural population of the viviparous tsetse fly. Ecological Entomology. 2016 Oct;41(5):618-26.

28. Tingley MW, Koo MS, Moritz C, Rush AC, Beissinger SR. The push and pull of climate change causes heterogeneous shifts in avian elevational ranges. Global Change Biology. 2012 Nov; 18(11):3279-90.

29. Gehne M, Hamill TM, Kiladis GN, Trenberth KE. Comparison of global precipitation estimates across a range of temporal and spatial scales. Journal of Climate. 2016 Nov 1;29(21):7773-95.

30. Eisikowitch D, Woodell SR. Some aspects of pollination ecology of Armeria maritima (Mill.) Willd. in Britain. New Phytologist. 1975 Mar;74(2):307-22.

31. Cnaani J, Thomson JD, Papaj DR. Flower choice and learning in foraging bumblebees: effects of variation in nectar volume and concentration. Ethology. 2006 Mar;112(3):27885.

32. Shahabuddin G, Ponte CA. Frugivorous butterfly species in tropical forest fragments: correlates of vulnerability to extinction. Biodiversity \& Conservation. 2005 May;14(5):1137-52.

33. WallisDeVries MF, Baxter W, Van Vliet AJ. Beyond climate envelopes: effects of weather on regional population trends in butterflies. Oecologia. 2011 Oct 1;167(2):559.

34. Weiss SB, Murphy DD. Thermal microenvironments and the restoration of rare butterfly habitat. Environmental Restoration. Island Press. Covelo. 1990:50-60.

35. Lenoir J, Graae BJ, Aarrestad PA, Alsos IG, Armbruster WS, Austrheim G, et al. Local temperatures inferred from plant communities suggest strong spatial buffering of climate warming across N orthern E urope. Global Change Biology. 2013 May;19(5):1470-81.

36. Villellas J, Morris WF, García MB. Variation in stochastic demography between and within central and peripheral regions in a widespread short-lived herb. Ecology. 2013 Jun;94(6):1378-88.

37. Pironon S, Papuga G, Villellas J, Angert AL, García MB, Thompson JD. Geographic variation in genetic and demographic performance: new insights from an old biogeographical paradigm. Biological Reviews. 2017 Nov;92(4):1877-909.

38. Geiger R, Aron RH, Todhunter P. The climate near the ground. Rowman \& Littlefield; 2009.

39. Collins M, Knutti R, Arblaster J, Dufresne JL, Fichefet T, Friedlingstein P, et al. Longterm climate change: projections, commitments and irreversibility. InClimate Change 2013-The Physical Science Basis: Contribution of Working Group I to the Fifth Assessment Report of the Intergovernmental Panel on Climate Change 2013 (pp. 10291136). Cambridge University Press.

40. Fridley JD. Downscaling climate over complex terrain: high finescale $(<1000 \mathrm{~m})$ spatial variation of near-ground temperatures in a montane forested landscape (Great Smoky 
Mountains). Journal of Applied Meteorology and Climatology. 2009 May 1;48(5):103349.

41. De Frenne P, Graae BJ, Rodríguez-Sánchez F, Kolb A, Chabrerie O, Decocq G, et al. Latitudinal gradients as natural laboratories to infer species' responses to temperature. Journal of Ecology. 2013 May;101(3):784-95.

42. Franklin J, Davis FW, Ikegami M, Syphard AD, Flint LE, Flint AL, et al. Modeling plant species distributions under future climates: how fine scale do climate projections need to be?. Global change biology. 2013 Feb;19(2):473-83.

43. Potter KA, Arthur Woods H, Pincebourde S. Microclimatic challenges in global change biology. Global change biology. 2013 Oct;19(10):2932-9.

44. Arnold RA, Arnold RA. Ecological studies of six endangered butterflies (Lepidoptera, Lycaenidae): island biogeography, patch dynamics, and the design of habitat preserves. Univ of California Press; 1983.

45. Hugall A, Moritz C, Moussalli A, Stanisic J. Reconciling paleodistribution models and comparative phylogeography in the Wet Tropics rainforest land snail Gnarosophia bellendenkerensis (Brazier 1875). Proceedings of the National Academy of Sciences. 2002 Apr 30;99(9):6112-7.

46. Graham CH, Moritz C, Williams SE. Habitat history improves prediction of biodiversity in rainforest fauna. Proceedings of the National Academy of Sciences. 2006 Jan 17;103(3):632-6.

47. Ruegg KC, Hijmans RJ, Moritz C. Climate change and the origin of migratory pathways in the Swainson's thrush, Catharus ustulatus. Journal of Biogeography. 2006 Jul;33(7):1172-82.

48. Baker RJ. The Karner blue butterfly: 1993 and beyond. Karner blue butterfly: A symbol of a van ishing landscape. Misc. Publ. 1994:84-1994.

49. US Fish and Wildlife Service. Update to KBB recovery plan; Inclusion of Michigan Oak Openings potential recovery unit. Greenbay, WI. 2011.

50. Haack RA. The endangered Karner blue butterfly (Lepidoptera: Lycaenidae): biology, management considerations, and data gaps.

51. Chan PK, Packer L. Assessment of potential Karner Blue butterfly (Lycaeides melissa samuelis)(family: Lycanidae) reintroduction sites in Ontario, Canada. Restoration Ecology. 2006 Dec;14(4):645-52.

52. Swengel AB, Swengel S. Observations of Karner Blues and the Barrens Butterfly Community in Wisconsin 1987-1993. Website: https://www. researchgate. net/publication/321037815. 1993.

53. Shuey JA. Dancing with fire: ecosystem dynamics, management, and the Karner blue (Lycaeides melissa samuelis Nabokov)(Lycaenidae). JOURNAL-LEPIDOPTERISTS SOCIETY. 1997;51:263-8.

54. Opler PA. A field guide to western butterflies. Houghton Mifflin Harcourt; 1999.

55. Grossmann EB, Mladenoff DJ. Open woodland and savanna decline in a mixeddisturbance landscape (1938 to 1998) in the Northwest Wisconsin (USA) Sand Plain. Landscape ecology. 2007 Dec;22(1):43-55. 
56. Schetter TA, Root KV. Assessing an imperiled oak savanna landscape in northwestern Ohio using Landsat data. Natural Areas Journal. 2011 Apr;31(2):118-30.

57. McKechnie AE, Wolf BO. Climate change increases the likelihood of catastrophic avian mortality events during extreme heat waves. Biology letters. 2010 Apr 23;6(2):253-6.

58. Sentis A, Hemptinne JL, Brodeur J. Parsing handling time into its components: implications for responses to a temperature gradient. Ecology. 2013 Aug;94(8):1675-80.

59. Hellmann JJ. The effect of an environmental change on mobile butterfly larvae and the nutritional quality of their hosts. Journal of Animal Ecology. 2002 Nov;71(6):925-36.

60. Jiguet F, Brotons L, Devictor V. Community responses to extreme climatic conditions. Current Zoology. 2011 Jun 1;57(3):406-13.

61. Cardoso P, Barton PS, Birkhofer K, Chichorro F, Deacon C, Fartmann T, Fukushima CS, Gaigher R, Habel JC, Hallmann CA, Hill MJ. Scientists' warning to humanity on insect extinctions. Biological Conservation. 2020 Feb 1;242:108426.

62. Lee TM, Jetz W. Unravelling the structure of species extinction risk for predictive conservation science. Proceedings of the Royal Society B: Biological Sciences. 2011 May 7;278(1710):1329-38.

63. Schultz CB, Crone EE. Using ecological theory to develop recovery criteria for an endangered butterfly. Journal of Applied Ecology. 2015 Oct 1;52(5):1111-5.

64. Semmens BX, Semmens DJ, Thogmartin WE, Wiederholt R, López-Hoffman L, Diffendorfer JE, et al. Quasi-extinction risk and population targets for the Eastern, migratory population of monarch butterflies (Danaus plexippus). Scientific reports. 2016 Mar 21;6(1):1-7.

65. Grundel R, Pavlovic NB, Sulzman CL. Nectar plant selection by the Karner blue butterfly (Lycaeides melissa samuelis) at the Indiana Dunes National Lakeshore. The American Midland Naturalist. 2000 Jul;144(1):1-0.

66. US Fish and Wildlife Service. Karner blue butterfly (Lycaeides melissa samuelis) Recovery Plan. Fort Snelling, Minnesota. 2003;221.

67. Potter KA, Arthur Woods H, Pincebourde S. Microclimatic challenges in global change biology. Global change biology. 2013 Oct;19(10):2932-9.

68. Hettinger A, Sanford E, Hill TM, Russell AD, Sato KN, Hoey J, Forsch M, Page HN, Gaylord B. Persistent carry-over effects of planktonic exposure to ocean acidification in the Olympia oyster. Ecology. 2012 Dec;93(12):2758-68.

69. Pincebourde S, Casas J. Warming tolerance across insect ontogeny: influence of joint shifts in microclimates and thermal limits. Ecology. 2015 Apr;96(4):986-97.

70. Klockmann M, Kleinschmidt F, Fischer K. Carried over: Heat stress in the egg stage reduces subsequent performance in a butterfly. PLoS One. 2017 Jul 14;12(7):e0180968.

71. Hernández Moresino RD, Gonçalves RJ, Helbling EW. Direct and indirect acquisition of photoprotective compounds in crab larvae of coastal Patagonia (Argentina). Journal of plankton research. 2014 May 1;36(3):877-82.

72. Fox J, Weisberg S. An R companion to applied regression. Sage publications; 2018 Sep 27.

73. Marshall DJ. Transgenerational plasticity in the sea: Context-dependent maternal effects across the life history. Ecology. 2008 Feb;89(2):418-27. 
74. Donelson JM, Wong M, Booth DJ, Munday PL. Transgenerational plasticity of reproduction depends on rate of warming across generations. Evolutionary Applications. 2016 Oct;9(9):1072-81.

75. Bowler K, Terblanche JS. Insect thermal tolerance: what is the role of ontogeny, ageing and senescence?. Biological Reviews. 2008 Aug;83(3):339-55.

76. Kingsolver JG, Arthur Woods H, Buckley LB, Potter KA, MacLean HJ, Higgins JK. Complex life cycles and the responses of insects to climate change.

77. Pahkala M, Laurila A, Merilä J. Carry-over effects of ultraviolet-B radiation on larval fitness in Rana temporaria. Proceedings of the Royal Society of London. Series B: Biological Sciences. 2001 Aug 22;268(1477):1699-706.

78. Fischer J, Phillips NE. Carry-over effects of multiple stressors on benthic embryos are mediated by larval exposure to elevated UVB and temperature. Global Change Biology. 2014 Jul;20(7):2108-16.

79. Levy O, Buckley LB, Keitt TH, Smith CD, Boateng KO, Kumar DS, Angilletta Jr MJ. Resolving the life cycle alters expected impacts of climate change. Proceedings of the Royal Society B: Biological Sciences. 2015 Aug 22;282(1813):20150837.

80. Fuller SG. Population dynamics of the endangered Karner blue butterfly (Lycaeides melissa samuelis Nabokov). State University of New York College of Environmental Science and Forestry; 2008.

81. Hellmann, J.J., Pelini, S.L., Prior, K.M. and Dzurisin, J.D., 2008. The response of two butterfly species to climatic variation at the edge of their range and the implications for poleward range shifts. Oecologia, 157(4), pp.583-592.

82. Stacey PB, Taper M. Environmental variation and the persistence of small populations. Ecological Applications. 1992 Feb;2(1):18-29.

83. Schultz CB, Chang GC. Challenges in insect conservation: Managing fluctuating populations in disturbed habitats. InConservation Biology 1998 (pp. 228-254). Springer, Boston, MA.

84. Omernik, J. M., \& Griffith, G. E. (2014). Ecoregions of the conterminous United States: evolution of a hierarchical spatial framework. Environmental management, 54(6), 12491266.

85. Roy DB, Rothery P, Moss D, Pollard E, Thomas JA. Butterfly numbers and weather: predicting historical trends in abundance and the future effects of climate change. Journal of Animal Ecology. 2001 Mar;70(2):201-17.

86. Watling JI, Brandt LA, Bucklin DN, Fujisaki I, Mazzotti FJ, Romanach SS, Speroterra C. Performance metrics and variance partitioning reveal sources of uncertainty in species distribution models. Ecological Modelling. 2015 Aug 10;309:48-59.

87. Daly C, Halbleib M, Smith JI, Gibson WP, Doggett MK, Taylor GH, et al. Physiographically sensitive mapping of climatological temperature and precipitation across the conterminous United States. International Journal of Climatology: a Journal of the Royal Meteorological Society. 2008 Dec;28(15):2031-64.

88. O’Donnell MS, Ignizio DA. Bioclimatic predictors for supporting ecological applications in the conterminous United States. US geological survey data series. 2012;691(10):4-9. 
89. Kingsolver JG, Arthur Woods H, Buckley LB, Potter KA, MacLean HJ, Higgins JK. Complex life cycles and the responses of insects to climate change.

90. Walsh KJ, Ryan BF. Tropical cyclone intensity increase near Australia as a result of climate change. Journal of Climate. 2000 Aug 15;13(16):3029-36.

91. Environmental Systems Research Institute. ArcGIS desktop: release 10.

92. Roberts DW, Cooper SV. Concepts and techniques of vegetation mapping. Land classifications based on vegetation: applications for resource management. 1989:90-6.

93. Wickham J, Stehman SV, Gass L, Dewitz JA, Sorenson DG, Granneman BJ, et al. Thematic accuracy assessment of the 2011 national land cover database (NLCD). Remote Sensing of Environment. 2017 Mar 15;191:328-41.

94. Herrando S, Titeux N, Brotons L, Anton M, Ubach A, Villero D, et al. Contrasting impacts of precipitation on Mediterranean birds and butterflies. Scientific reports. 2019 Apr 5;9(1):1-7.

95. Jo B, Laitila T. Comparisons of Some Weighting Methods for Non-response Adjustment. Lithuanian Journal of Statistics. 2015 Dec 20;54(1):69-83.

96. Kuhn M. Caret: classification and regression training. Astrophysics Source Code Library. 2015 May:ascl-1505.

97. McCarl B, Norton R, Wu X. Assessing Climate Change Effects of IDB Projects: Concepts and Procedures. American Development Bank Washington. 2014 Dec.

98. Ward EJ, Holmes EE, Thorson JT, Collen B. Complexity is costly: a meta-analysis of parametric and non-parametric methods for short-term population forecasting. Oikos. 2014 Jun;123(6):652-61.

99. Saeys Y, Inza I, Larranaga P. A review of feature selection techniques in bioinformatics. bioinformatics. 2007 Oct 1;23(19):2507-17.

100. Mitchell M. An introduction to genetic algorithms. MIT press; 1998.

101. Kucheryavskiy S. mdatools-R package for chemometrics. Chemometrics and Intelligent Laboratory Systems. 2020 Mar 15;198:103937.

102. Kennedy JB, Neville AM. Basic statistical methods for engineers and scientists. Crowell; 1976.

103. Ward EJ, Holmes EE, Thorson JT, Collen B. Complexity is costly: a meta-analysis of parametric and non-parametric methods for short-term population forecasting. Oikos. 2014 Jun;123(6):652-61.

104. Nowicki P, Bonelli S, Barbero F, Balletto E. Relative importance of densitydependent regulation and environmental stochasticity for butterfly population dynamics. Oecologia. 2009 Aug;161(2):227-39.

105. Băncilă RI, Ozgul A, Hartel T, Sos T, Schmidt BR. Direct negative density-dependence in a pond-breeding frog population. Ecography. 2016 May;39(5):449-55.

106. Opdam P, Wascher D. Climate change meets habitat fragmentation: linking landscape and biogeographical scale levels in research and conservation. Biological conservation. 2004 May 1;117(3):285-97. 
107. Oliver TH, Marshall HH, Morecroft MD, Brereton T, Prudhomme C, Huntingford C. Interacting effects of climate change and habitat fragmentation on drought-sensitive butterflies. Nature Climate Change. 2015 Oct;5(10):941-5.

108. Fuller SG. Population dynamics of the endangered Karner blue butterfly (Lycaeides melissa samuelis Nabokov). State University of New York College of Environmental Science and Forestry; 2008.

109. Swengel SR, Schlicht D, Olsen F, Swengel AB. Declines of prairie butterflies in the midwestern USA. Journal of Insect Conservation. 2011 Apr;15(1):327-39.

110. Freckleton RP, Watkinson AR, Green RE, Sutherland WJ. Census error and the detection of density dependence. Journal of Animal Ecology. 2006 Jul;75(4):837-51.

111. Grundel R, Pavlovic NB, Sulzman CL. The effect of canopy cover and seasonal change on host plant quality for the endangered Karner blue butterfly (Lycaeidesmelissasamuelis). Oecologia. 1998 Apr 1;114(2):243-50.

112. Dennis RL, Sparks TH. Climate signals are reflected in an 89 year series of British Lepidoptera records. European Journal of Entomology. 2007 Oct 1;104(4):763.

113. Defra. Adapting to climate change-UK climate projections. Uk Clim Proj. 2009.

114. Jenkins GJ, Murphy JM, Sexton DM, Lowe JA, Jones P, Kilsby CG. UK Climate Projections briefing report.

115. McDermott Long O, Warren R, Price J, Brereton TM, Botham MS, Franco AM. Sensitivity of UK butterflies to local climatic extremes: which life stages are most at risk?. Journal of Animal Ecology. 2017 Jan;86(1):108-16.

116. Klockmann M, Kleinschmidt F, Fischer K. Carried over: Heat stress in the egg stage reduces subsequent performance in a butterfly. PLoS One. $2017 \mathrm{Jul}$ 14;12(7):e0180968.

117. Wiklund C, Lindfors V, Forsberg J. Early male emergence and reproductive phenology of the adult overwintering butterfly Gonepteryx rhamni in Sweden. Oikos. 1996 Mar 1:227-40.

118. McLaughlin JF, Hellmann JJ, Boggs CL, Ehrlich PR. Climate change hastens population extinctions. Proceedings of the National Academy of Sciences. 2002 Apr 30;99(9):6070-4.

119. Patterson TA, Grundel R, Dzurisin JD, Knutson RL, Hellmann JJ. Evidence of an extreme weather-induced phenological mismatch and a local extirpation of the endangered Karner blue butterfly. Conservation Science and Practice. 2020 Jan;2(1):e147.

120. Harvell CD, Mitchell CE, Ward JR, Altizer S, Dobson AP, Ostfeld RS, Samuel MD. Climate warming and disease risks for terrestrial and marine biota. Science. 2002 Jun 21;296(5576):2158-62.

121. Shingleton AW. Evolution and the regulation of growth and body size. Mechanisms of life history evolution. 2011:43-55.

122. Dennis RL. Butterflies and climate change. Manchester University Press; 1993. 123. Roy DB, Rothery P, Moss D, Pollard E, Thomas JA. Butterfly numbers and weather: predicting historical trends in abundance and the future effects of climate change. Journal of Animal Ecology. 2001 Mar;70(2):201-17. 
124. Horne CR, Hirst AG, Atkinson D. Temperature-size responses match latitudinal-size clines in arthropods, revealing critical differences between aquatic and terrestrial species. Ecology letters. 2015 Apr;18(4):327-35.

125. Fenberg PB, Self A, Stewart JR, Wilson RJ, Brooks SJ. Exploring the universal ecological responses to climate change in a univoltine butterfly. Journal of Animal Ecology. 2016 May;85(3):739-48.

126. Sheridan JA, Bickford D. Shrinking body size as an ecological response to climate change. Nature climate change. 2011 Nov;1(8):401-6.

127. Bristow LV. Effects of Warming on the Endangered Karner Blue Butterfly: An Exploration of the Sensitivity of Life History Stages and Traits. University of Notre Dame; 2017.

128. Checa MF, Levy E, Rodriguez J, Willmott K. Rainfall as a significant contributing factor to butterfly seasonality along a climatic gradient in the neotropics. bioRxiv. 2019 Jan 1:630947.

129. McDermott Long O, Warren R, Price J, Brereton TM, Botham MS, Franco AM. Sensitivity of UK butterflies to local climatic extremes: which life stages are most at risk?. Journal of Animal Ecology. 2017 Jan;86(1):108-16.

130. Lawson CR, Bennie JJ, Thomas CD, Hodgson JA, Wilson RJ. Local and landscape management of an expanding range margin under climate change. Journal of Applied Ecology. 2012 Jun;49(3):552-61.

131. Lawson CR, Bennie CD, Thomas JA, Hodgson T, Bernhard PA, Budd A, et al. The status and conservation of the silver-spotted skipper Hesperia comma in South-East England 2000-2009. University of Exeter, Exeter, UK. 2013.

132. Brown RD, Kenny N, Corry RC. Testing the microclimatic habitat design framework in abandoned sand and gravel extraction sites using the Karner blue butterfly. Ecological Restoration. 2011 Mar 1;29(1-2):52-63.

133. Davies ZG, Wilson RJ, Coles S, Thomas CD. Changing habitat associations of a thermally constrained species, the silver-spotted skipper butterfly, in response to climate warming. Journal of Animal Ecology. 2006 Jan;75(1):247-56.

134. O'Brien DM, Boggs CL, Fogel ML. Making eggs from nectar: the role of life history and dietary carbon turnover in butterfly reproductive resource allocation. Oikos. 2004 May;105(2):279-91.

135. Guiney MS, Andow DA, Wilder TT. Metapopulation structure and dynamics of an endangered butterfly. Basic and Applied Ecology. 2010 Jun 1;11(4):354-62.

136. Pollard E, Yates TJ, Owen DF. Monitoring butterflies for ecology and conservation. Trends in Ecology and Evolution. 1994;9(1):31.

137. Austin MP. Spatial prediction of species distribution: an interface between ecological theory and statistical modelling. Ecological modelling. 2002 Nov 30;157(23):101-18.

138. Austin M. Species distribution models and ecological theory: a critical assessment and some possible new approaches. Ecological modelling. 2007 Jan 10;200(1-2):1-9. 
139. Sinclair BJ, Marshall KE, Sewell MA, Levesque DL, Willett CS, Slotsbo S, et al. Can we predict ectotherm responses to climate change using thermal performance curves and body temperatures?. Ecology Letters. 2016 Nov;19(11):1372-85.

140. Frazier MR, Huey RB, Berrigan D. Thermodynamics constrains the evolution of insect population growth rates:"warmer is better". The American Naturalist. 2006 Oct;168(4):512-20.

141. Savage VM, Gillooly JF, Brown JH, West GB, Charnov EL. Effects of body size and temperature on population growth. The American Naturalist. 2004 Mar;163(3):42941.

142. Kingsolver JG. The Well-Temperatured Biologist: (American Society of Naturalists Presidential Address). The American Naturalist. 2009 Dec;174(6):755-68.

143. Zimmermann NE, Yoccoz NG, Edwards TC, Meier ES, Thuiller W, Guisan A, et al. Climatic extremes improve predictions of spatial patterns of tree species. Proceedings of the National Academy of Sciences. 2009 Nov 17;106(Supplement 2):19723-8.

144. Kellermann V, Overgaard J, Hoffmann AA, Fløjgaard C, Svenning JC, Loeschcke V. Upper thermal limits of Drosophila are linked to species distributions and strongly constrained phylogenetically. Proceedings of the National Academy of Sciences. 2012 Oct 2;109(40):16228-33.

145. McDermott Long O, Warren R, Price J, Brereton TM, Botham MS, Franco AM. Sensitivity of UK butterflies to local climatic extremes: which life stages are most at risk? Journal of Animal Ecology. 2017 Jan;86(1):108-16.

146. Holl KD. Nectar resources and their influence on butterfly communities on reclaimed coal surface mines. Restoration Ecology. 1995 Jun;3(2):76-85.

147. Lane CP, Andow DA. Oak savanna subhabitat variation and the population biology of Lycaeides melissa samuelis (Lepidoptera: Lycaenidae). Annals of the Entomological Society of America. 2003 Nov 1;96(6):799-809.

148. Grundel R, Pavlovic NB. Resource availability, matrix quality, microclimate, and spatial pattern as predictors of patch use by the Karner blue butterfly. Biological Conservation. 2007 Feb 1;135(1):135-44.

149. Plowright RC. Nectar production in the boreal forest lily Clintonia borealis. Canadian Journal of Botany. 1981 Feb 1;59(2):156-60.

150. Plowright RC. Corolla depth and nectar concentration: an experimental study. Canadian Journal of Botany. 1987 May 1;65(5):1011-3.

151. Cresswell JE, Galen C. Frequency-dependent selection and adaptive surfaces for floral character combinations: the pollination of Polemonium viscosum. The American Naturalist. 1991 Dec 1;138(6):1342-53.

152. Nicolson SW, Nepi M, Pacini E, editors. Nectaries and nectar. Dordrecht: Springer; 2007 Apr 18.

153. Turner JR, Gatehouse CM, Corey CA. Does solar energy control organic diversity? Butterflies, moths and the British climate. Oikos. 1987 Feb 1:195-205.

154. Currie DJ. Energy and large-scale patterns of animal-and plant-species richness. The American Naturalist. 1991 Jan 1;137(1):27-49. 
155. Hawkins BA, Porter EE. Does herbivore diversity depend on plant diversity? The case of California butterflies. The American Naturalist. 2003 Jan;161(1):40-9.

156. Brown RD, Kenny N, Corry RC. Testing the microclimatic habitat design framework in abandoned sand and gravel extraction sites using the Karner blue butterfly. Ecological Restoration. 2011 Mar 1;29(1-2):52-63.

157. Clausen HD, Holbeck HB, Reddersen J. Factors influencing abundance of butterflies and burnet moths in the uncultivated habitats of an organic farm in Denmark. Biological Conservation. 2001 Apr 1;98(2):167-78.

158. Geiger R, Aron RH, Todhunter P. The climate near the ground. Rowman \& Littlefield; 2009.

159. García D, Zamora R, Gómez JM, Jordano P, Hódar JA. Geographical variation in seed production, predation and abortion in Juniperus communis throughout its range in Europe. Journal of Ecology. 2000 Jun;88(3):435-46.

160. Bjørnstad ON, Grenfell BT. Noisy clockwork: time series analysis of population fluctuations in animals. Science. 2001 Jul 27;293(5530):638-43.

161. Deutsch CA, Tewksbury JJ, Huey RB, Sheldon KS, Ghalambor CK, Haak DC, et al. Impacts of climate warming on terrestrial ectotherms across latitude. Proceedings of the National Academy of Sciences. 2008 May 6;105(18):6668-72.

162. Omernik JM, Griffith GE. Ecoregions of the conterminous United States: evolution of a hierarchical spatial framework. Environmental management. 2014 Dec;54(6):1249-66.

163. Hällfors MH, Liao J, Dzurisin J, Grundel R, Hyvärinen M, Towle K, et al. Addressing potential local adaptation in species distribution models: implications for conservation under climate change. Ecological Applications. 2016 Jun;26(4):1154-69.

\section{Supporting Information}

S1 Table 1. The states, counties, latitudes, and longitudes of $48 \mathrm{Kbb}$ populations in five ecoregions.

S1 Table 2. Summaries of long-term Karner blue population count data during flight periods, including sampling methods, sampled populations, dates \& durations, and data contributors.

\section{S1 Table 3. Descriptions of each category of density independent data used to model} populations of the Kbb.

S1 Table 4. Performance comparisons for six modeling algorithms used to select significant predictors describing adult abundance of first and second generation Kbb population. Abbreviations used: MAE_-Mean Absolute Error, RMSE_-Root-Mean-Square Error, $\mathrm{R}^{2}$-adjadjusted R-squared, GLM — Generalized Linear Model, MARS — Multivariate additive regression spline, GBM — Gradient Boost Machines, RF-Random Forest, ANN—Neural Network Analysis, SVM-Support Vector Machines. The top three models for each of the accuracy metrics were bolded. 
812 S1 Fig 1. EPA ecoregions level III illustrating the ecoregions associated with the study sites.

813 The five groups of the Karner blue populations (Central Wisconsin, Northwest Wisconsin, Fort

814 McCoy, Indiana Dunes National Park, and Albany Pine Bush) belong to five distinct ecoregions

815 (North Central Harwood Forests, Northern Lakes and Forests, Driftless Area, Southern

816 Michigan/Northern Indiana Drift Plain, and Northeastern Coastal Zone, respectively).

817

818 S2 Sample R codes of statistical analysis and modeling 
Northwestern Wisconsin

13 Populations

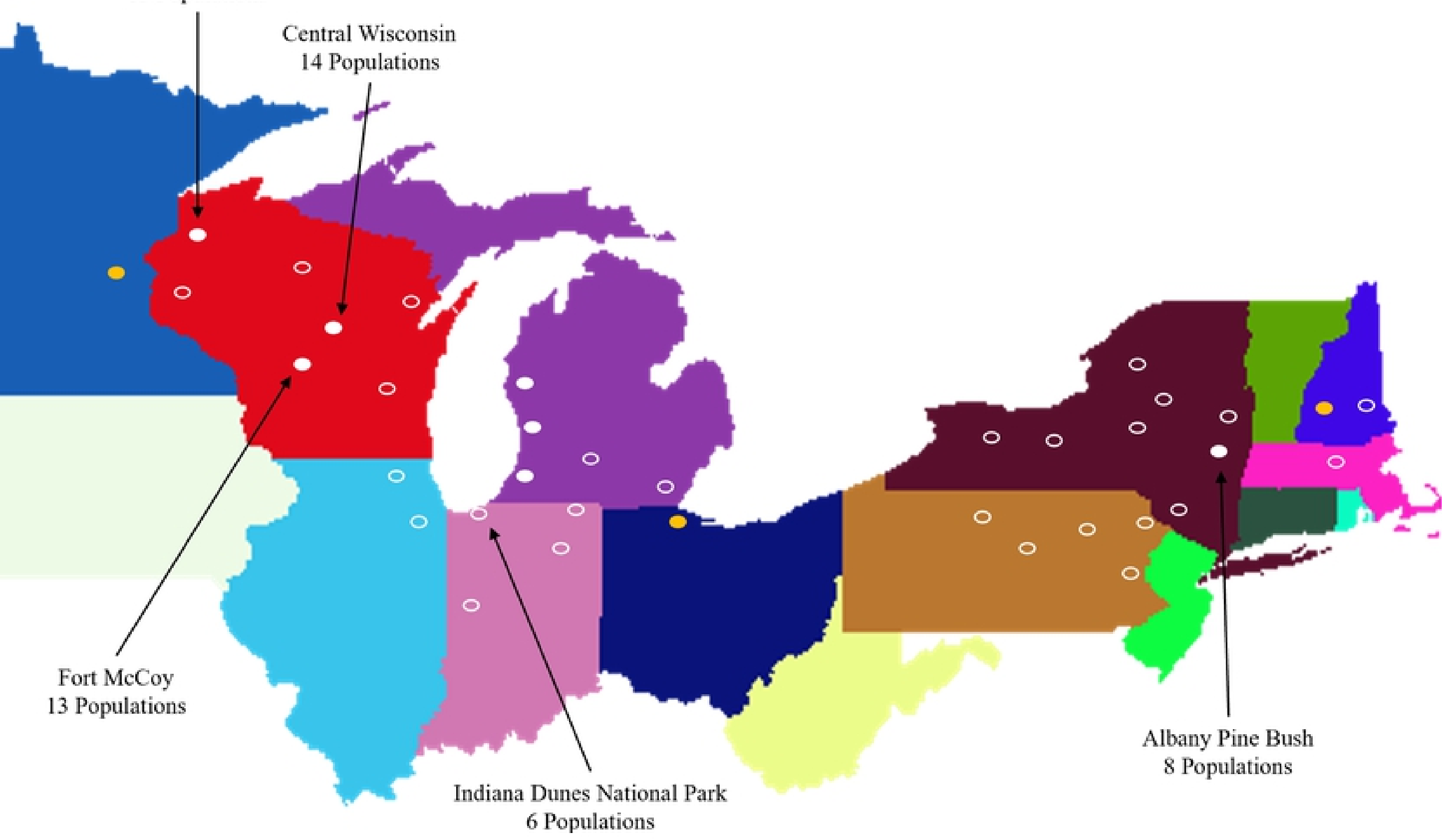

Figure 